\title{
Technical note: Changes to herd cutoff date in conception rate evaluations
}

\author{
J. L. Hutchison, ${ }^{1}$ P. M. VanRaden, H. D. Norman, and J. B. Cole \\ Animal Improvement Programs Laboratory, Agricultural Research Service, US Department of Agriculture, Beltsville, MD 20705-2350
}

\begin{abstract}
Service-sire conception rate (SCR) evaluations were implemented for the United States in August 2008. Only inseminations from the most recent $4 \mathrm{yr}$ of breeding records are used for SCR evaluations, and all inseminations must have occurred $\geq 70 \mathrm{~d}$ before the data submission deadline for an evaluation. In April 2012, edits for SCR were modified so that all inseminations must have occurred $\geq 70 \mathrm{~d}$ before the last herd test date rather than the constant date of $70 \mathrm{~d}$ before the data submission deadline. This edit more precisely measures the days of opportunity for a cow to be diagnosed as pregnant or not pregnant following insemination, and is herd specific. The number of inseminations before the edit change was 16,906,385 compared with 16,492,331 after the edit change. Correlations of SCR before and after the edit change were 0.96 for Holsteins and slightly lower for other breeds, with little change in mean or standard deviation. Weekly mean conception rates after the edit change were more stable for the most recent inseminations. The conception rate was $60 \%$ at wk 10 before the constant cutoff date (before edit change) compared with $42 \%$ at 10 wk before the last herd test date (after the edit change). Similar edits to SCR are applied to heifer conception rate (HCR) and cow conception rate data (CCR), and were changed in August 2012 to use herd-specific cutoff dates. The HCR and CCR correlations before and after the edit change were 0.99 or higher for all breeds, with little change in mean or standard deviation. The new edits improve accuracy of SCR, HCR, and CCR evaluations by accounting for differing opportunity to confirm pregnancy caused by discontinued testing or differences in herd testing schedules.
\end{abstract}

Key words: conception rate, fertility, evaluation

\section{Technical Note}

Service-sire conception rate (SCR), a phenotypic fertility evaluation based on conventional (nonsexed)

Received September 26, 2012.

Accepted October 23, 2012.

${ }^{1}$ Corresponding author: Jana.Hutchison@ars.usda.gov inseminations from parities 1 through 5 , was implemented for the United States in August 2008 (Norman et al., 2008a,b). The SCR model included the categorical fixed effects of parity for lactations 1 through 5, stateyear-month of insemination group, 6 standardized milk yield groups, number of inseminations 1 to 7 , cow age at breeding, and herd-year-season-parity-registry status class. Covariate effects included service-sire and mating inbreeding coefficients, which were linear regressions fit as deviations from the overall mean. Random effects included service-sire age group, AI organization-insemination year group, individual service sire, cow's genetic ability to conceive, cow's permanent environmental effect, and residual error. Lactation length at breeding was limited to 30 to 365 DIM. The cow age limit was 2 to $15 \mathrm{yr}$, defined by rounding the cow's actual age (days/365.25) to the nearest whole number. Because lactations were restricted to 5 and earlier, cow ages at breeding beyond 8 yr were infrequent; thus, if age was beyond $8 \mathrm{yr}$, cow age group was set to 8 (Kuhn et al., 2008). Inseminations were also eliminated if consecutive services were within $10 \mathrm{~d}$ of each other, with only information from the later service kept. Inseminations were limited to the $4 \mathrm{yr}$ preceding the evaluation date.

To provide ample time to diagnose breedings as successful or not, inseminations were required to be $70 \mathrm{~d}$ before the data submission deadline. Inseminations were confirmed successful or not by using other reproductive events (heats, subsequent breedings, positive and negative pregnancy checks, and subsequent calving dates), do-not-breed designations, and termination codes, indicating that cows were sold for reproductive problems. A preliminary study (J. Hutchison, unpublished data) found that $83 \%$ of lactations had a pregnancy check, $14 \%$ could not be confirmed, $2 \%$ were sold due to reproductive reasons, and $1 \%$ had a do-not-breed designation. Such variables are updated continuously in herd management software but are only uploaded to the national database at each herd test day. Many herds test each month, but some herds test every other month or discontinue testing, causing a wide range of opportunity periods among herds.

Edits for SCR were modified in the April 2012 evaluations to use the most recent test date for each herd, rather than a uniform cutoff date for all SCR 
Table 1. Number and percentage of inseminations by pregnancy confirmation status for all breeds

\begin{tabular}{lrr}
\hline & \multicolumn{2}{c}{ Inseminations } \\
\cline { 2 - 3 } Confirmation status & $\mathrm{n}$ & $\%$ \\
\hline Cannot determine & 598,532 & 3.23 \\
Confirmed open by another reproductive event & $11,696,340$ & 63.05 \\
Confirmed open by pregnancy check & 258,291 & 1.39 \\
Confirmed open by subsequent calving date & 161,427 & 0.87 \\
Confirmed sold for reproductive reasons & 87,696 & 0.47 \\
Confirmed pregnant by pregnancy check & $1,541,137$ & 8.31 \\
Confirmed pregnant by subsequent calving date & $4,116,254$ & 22.19 \\
Do-not-breed designation & 90,919 & 0.49 \\
\hline
\end{tabular}

data (Hutchison and Norman, 2012). If dairy records processing centers routinely forwarded data from herds that use labor-efficient records, this change would have not been needed. Each breeding for a given herd must have occurred $70 \mathrm{~d}$ before the herd's most recent test date to be considered in SCR. Other reproductive events or subsequent calvings occurring after the herd cutoff are still used to confirm earlier breedings. To compare evaluations before and after the edit change, means, standard deviations, and correlations were calculated between 2 consecutive evaluations and within the same evaluation using SAS (version 9.3; SAS Institute, 2011). Weekly mean conception rates, up to wk 20 before the cutoff date, were also calculated before and after the edit change using the same data to show when the conception rate stabilized among the most recent breedings.

The number of herds performing pregnancy checks and the reasons that inseminations were confirmed as successful or not were collected. The number of inseminations and percentages for each reason are shown in Table 1. Most inseminations were confirmed open by other reproductive events (63\%) or confirmed pregnant by the subsequent calving date $(22 \%)$. Inseminations were not used if they could not be confirmed (3\%), such as the last breeding for the last lactation on file if there was no other reproductive event. Other fertility evaluations discarded inseminations that had neither a corresponding pregnancy check nor a subsequent insemination event within $90 \mathrm{~d}$ after the date of breeding (Weigel, 2004). Current edits for the national fertility evaluations include more records by allowing later abortion, pregnancy, calving, and disposal records to confirm status. An alternative to data cutoff edits may be failure time analysis, treating the latest observations as censored (Weigel, 2004).

The female fertility traits (heifer conception rate, HCR; and cow conception rate, CCR) also used a constant cutoff date, and were modified in the August 2012 evaluations to be consistent with SCR (Hutchison et al., 2012). Previous studies showed that female fertility traits may be sensitive to the edit limits and time periods included. For pregnancy rate, lower and upper limits had large effects on heritability and genetic variance (Oseni et al., 2004). For conception rate, a subsequent calving was required to confirm success in some research studies (Huang et al., 2008), but records need to be used sooner in routine evaluations.

Fertility edits in other countries were examined. France and the Czech Republic also use conception rate as a female fertility trait, and the French edits discard inseminations performed $<6$ mo before evaluation date (Interbull, 2012). Furthermore, when no subsequent calving occurs, the last insemination is considered as

Table 2. Sire conception rate correlations from consecutive evaluations before and after the edit change, and the same evaluation before and after the edit change

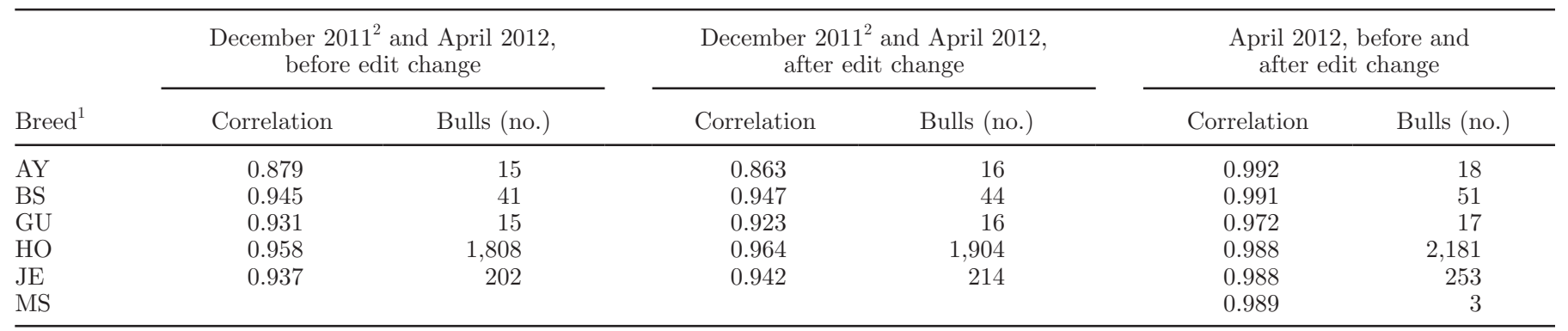

${ }^{1} \mathrm{AY}=$ Ayrshire; BS = Brown Swiss; GU = Guernsey; HO = Holstein; JE = Jersey; MS = Milking Shorthorn.

${ }^{2}$ December 2011 evaluation was before the edit change. 
Table 3. Sire conception rate mean and standard deviations from consecutive evaluations before and after the edit change

\begin{tabular}{|c|c|c|c|c|c|c|c|c|c|}
\hline \multirow[b]{3}{*}{ Breed $^{1}$} & \multicolumn{3}{|c|}{ December 2011} & \multicolumn{6}{|c|}{ April 2012} \\
\hline & \multicolumn{3}{|c|}{ Before edit change } & \multicolumn{3}{|c|}{ Before edit change } & \multicolumn{3}{|c|}{ After edit change } \\
\hline & Bulls (no.) & Mean (\%) & $\mathrm{SD}(\%)$ & Bulls (no.) & Mean $(\%)$ & $\mathrm{SD}(\%)$ & Bulls (no.) & Mean $(\%)$ & $\mathrm{SD}(\%)$ \\
\hline $\mathrm{AY}$ & 17 & 0.01 & 1.83 & 18 & -0.01 & 2.44 & 19 & 0.01 & 2.29 \\
\hline BS & 49 & 0.00 & 2.38 & 51 & 0.00 & 2.50 & 54 & 0.00 & 2.49 \\
\hline GU & 18 & -0.01 & 1.45 & 18 & -0.01 & 1.48 & 18 & 0.00 & 1.40 \\
\hline MS & 2 & 0.00 & 0.28 & 4 & 0.00 & 1.03 & 3 & 0.00 & 1.01 \\
\hline
\end{tabular}

${ }^{1} \mathrm{AY}=$ Ayrshire; BS = Brown Swiss; GU = Guernsey; HO = Holstein; JE = Jersey; and MS = Milking Shorthorn.

a success, except when DIM in the current lactation is more than $260 \mathrm{~d}$ and the insemination was older than $340 \mathrm{~d}$ (when the cow was likely to have been culled for reproductive reasons). Many countries use nonreturn rate to a predefined number of days, such as 56 or 70 , as a measure of fertility because edits are simple. As an example, the Canadian female fertility evaluation measures 56-d nonreturn rate, with inseminations occurring $56 \mathrm{~d}$ or more before a constant data cutoff being discarded (Interbull, 2012). However, nonreturn is a poor measure of female fertility because cows that do not show heat again quickly are considered successes. In addition, herds doing the best job of heat detection and timely rebreeding are rated with the lowest nonreturn rate. Conception rate is a more valuable trait, but requires more complex edits. Means, standard deviations, and correlations using the same data before and after the edit change were calculated for HCR and CCR with SAS (version 9.3; SAS Institute, 2011).

There were $16,433,710$ inseminations used in the December 2011 evaluation, 16,906,385 inseminations in April 2012 before the edit change, and 16,492,331 used in April 2012 after the edit change. The number of inseminations decreased after the edit change because of herds discontinuing testing and the timeframe of the herd's last test date. The SCR correlations (Table 2) between 2 consecutive evaluations before and after the edit change were 0.96 for Holstein bulls and slightly lower in other breeds. The lowest correlation was 0.86 for Ayrshire bulls comparing only 16 bulls, each with few observations. Rank correlations using the Spearman option in the CORR procedure in SAS (version 9.3; SAS Institute, 2011) were 0.70 for Ayrshire, 0.93 for Brown Swiss, 0.92 for Guernsey, 0.95 for Holstein, and 0.92 for Jersey cattle (not shown in table). This indicates that the changes to the edits did result in some reranking of sires. Correlations comparing the same data from the same evaluation before and after the edit change were 0.97 or greater. Little change in mean or standard deviation (Table 3) occurred before and after the edit change, with Holstein bulls having a 0.00 mean and 2.10 standard deviation in the April 2012 evaluation after changes to the edits.

Weekly mean conception rates across and within herd were calculated from breedings that occurred 7 to $20 \mathrm{wk}$ before the cutoff date before the edit change

Table 4. Weekly across- and within-herd conception rate mean and standard deviations before the edit change for all breeds

\begin{tabular}{|c|c|c|c|c|c|c|}
\hline $\begin{array}{l}\text { Week before } \\
\text { cutoff date }\end{array}$ & \multicolumn{3}{|c|}{ Across herd } & \multicolumn{3}{|c|}{ Within herd } \\
\hline 7 & 120,092 & 87 & 34 & 10,306 & 90 & 20 \\
\hline 9 & 126,397 & 68 & 47 & 10,673 & 76 & 29 \\
\hline 10 & 130,605 & 60 & 49 & 10,856 & 69 & 31 \\
\hline 11 & 133,414 & 54 & 50 & 11,071 & 63 & 32 \\
\hline 14 & 140,357 & 44 & 50 & 11,252 & 52 & 33 \\
\hline 15 & 140,654 & 43 & 50 & 11,282 & 51 & 33 \\
\hline 16 & 141,416 & 42 & 49 & 11,264 & 50 & 33 \\
\hline 17 & 140,356 & 41 & 49 & 11,114 & 49 & 33 \\
\hline 18 & 142,969 & 40 & 49 & 11,084 & 48 & 33 \\
\hline 19 & 142,355 & 39 & 49 & 11,024 & 47 & 32 \\
\hline 20 & 145,092 & 39 & 49 & 11,025 & 47 & 32 \\
\hline
\end{tabular}


Table 5. Weekly across- and within-herd conception rate mean and standard deviations after the edit change for all breeds

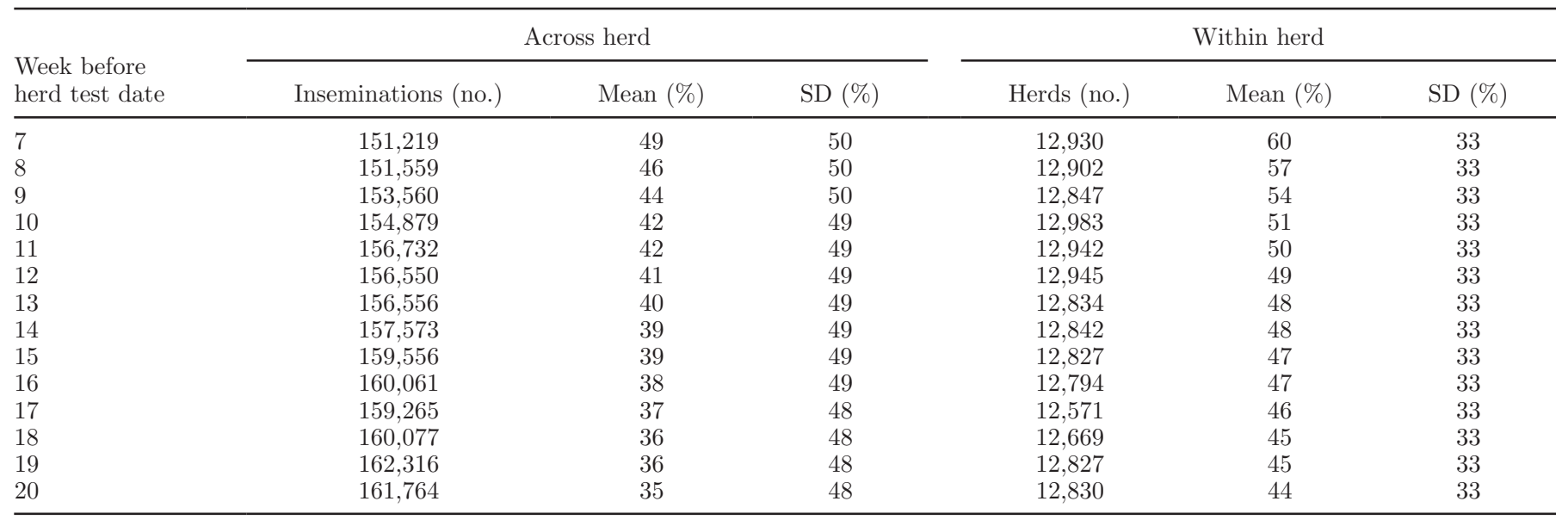

(Table 4) and before herd test date after the edit change (Table 5). Observations that occurred closest to the evaluation date might be measuring nonreturn rate rather than conception rate because fewer of the cows are confirmed pregnant or will maintain the pregnancy to term. Before the edit change, breedings would be deleted from the SCR evaluation before the 10-wk mark, with a conception rate of $60 \%$. Between wk 10 and 20 , there was a 21-percentage point decrease. After the edit change (Table 5), the trend from 10 to 20 wk was much less dramatic with a herd-specific cutoff (a difference of 7 percentage points). The standard deviation of the within-herd conception rate stabilized much earlier (about wk 7) in the new approach, as opposed to wk 11 in the original method.

Little change occurred in means and standard deviations for HCR (Table 6) before and after the edit change using the same data. Correlations were $>0.99$ for all breeds. Similar results for CCR are reported in Table 7, except for Milking Shorthorn bulls.

Because $83 \%$ of lactations are confirmed by a pregnancy check and all unconfirmed breedings are discarded, this herd-specific edit more precisely measures the days of opportunity for a cow to be diagnosed as pregnant or not pregnant following insemination without having to discard an excessive amount of the most recent inseminations. The new edits improve the accuracy of SCR, HCR, and CCR evaluations by accounting for differing opportunity to confirm pregnancy caused by discontinued testing or differences in herd testing schedules and results in more stable conception rates among the most recent inseminations. This change was implemented in April 2012 for SCR and in August 2012 for HCR and CCR.

\section{ACKNOWLEDGMENTS}

The cooperation of the dairy records processing centers (AgriTech Analytics, Visalia, CA; AgSource Cooperative Services, Verona, WI; DHI Computing Service, Provo, UT; and Dairy Records Management Systems, Raleigh, NC, and Ames, IA) in supplying reproductive reports is acknowledged. The authors thank Mel DeJarnette (Select Sires Inc., Plain City, OH), Kent Weigel (Department of Dairy Science, University of Wisconsin, Madison), and the National Association of Animal Breeders' Fertility Committee for helpful comments regarding fertility edits. Two anonymous review-

Table 6. Heifer conception rate mean, standard deviation, and correlations before and after the edit change

\begin{tabular}{|c|c|c|c|c|c|c|c|c|}
\hline \multirow[b]{2}{*}{ Breed $^{1}$} & \multicolumn{3}{|c|}{ Before edit change } & \multicolumn{3}{|c|}{ After edit change } & \multirow[b]{2}{*}{ Correlation } & \multirow[b]{2}{*}{ Bulls (no.) } \\
\hline & Bulls (no.) & Mean (\%) & $\mathrm{SD}(\%)$ & Bulls (no.) & Mean (\%) & $\mathrm{SD}(\%)$ & & \\
\hline BS & 953 & -0.17 & 0.72 & 948 & -0.21 & 0.71 & 0.991 & 948 \\
\hline GU & 478 & -0.02 & 0.66 & 475 & -0.03 & 0.71 & 0.993 & 475 \\
\hline $\mathrm{HO}$ & 34,846 & 0.26 & 1.19 & 34,718 & 0.27 & 1.18 & 0.997 & 34,715 \\
\hline $\mathrm{JE}$ & 3,555 & 0.27 & 1.07 & 3,534 & 0.30 & 1.06 & 0.996 & 3,534 \\
\hline
\end{tabular}

${ }^{1} \mathrm{AY}=$ Ayrshire; BS = Brown Swiss; GU = Guernsey; HO = Holstein; JE = Jersey; MS = Milking Shorthorn.

${ }^{2} \mathrm{An}$ additional edit for breed purity was decreased from 97 to $75 \%$ for the Milking Shorthorn breed to allow more records to be included. 
Table 7. Cow conception rate mean, standard deviation, and correlations before and after the edit change

\begin{tabular}{|c|c|c|c|c|c|c|c|c|}
\hline Breed $^{1}$ & \multicolumn{3}{|c|}{ Before edit change } & \multicolumn{3}{|c|}{ After edit change } & Correlation & Bulls (no.) \\
\hline $\mathrm{AY}$ & 1,009 & -0.05 & 1.19 & 993 & -0.02 & 1.18 & 0.995 & 993 \\
\hline GU & 1,213 & -0.37 & 1.93 & 1,204 & -0.40 & 1.94 & 0.997 & 1,204 \\
\hline $\mathrm{HO}$ & 61,707 & -0.02 & 1.73 & 61,768 & -0.02 & 1.73 & 0.997 & 61,379 \\
\hline JE & 7,883 & 0.30 & 1.68 & 7,819 & 0.27 & 1.68 & 0.995 & 7,819 \\
\hline
\end{tabular}

${ }^{1} \mathrm{AY}=$ Ayrshire; BS = Brown Swiss; GU = Guernsey; HO = Holstein; JE = Jersey; and MS = Milking Shorthorn.

${ }^{2}$ An additional edit for breed purity was decreased from 97 to $75 \%$ for the Milking Shorthorn breed to allow more records to be included.

ers are thanked for providing valuable feedback on the manuscript.

\section{REFERENCES}

Huang, C., S. Tsuruta, J. K. Bertrand, I. Misztal, T. J. Lawlor, and J. S. Clay. 2008. Environmental effects on conception rates of Holsteins in New York and Georgia. J. Dairy Sci. 91:818-825.

Hutchison, J., and H. D. Norman. 2012. Changes to evaluation system (April 2012). Data cutoff date for sire conception rate. Accessed Sep. 17, 2012. http://aipl.arsusda.gov/reference/changes/chglst. cfm?run=1204.

Hutchison, J., P. VanRaden, M. Tooker, J. Megonigal, and G. Fok. 2012. Changes to evaluation system (August 2012). Revisions to heifer and cow conception rates. Accessed Sep. 17, 2012. http:// aipl.arsusda.gov/reference/changes/chglst.cfm?run $=1208$.

Interbull. 2012. Description of National Genetic Evaluation Systems for dairy cattle traits as applied in different Interbull member countries. Accessed July 9, 2012. http://www-interbull.slu.se/ national_ges_info2/framesida-ges.htm.
Kuhn, M. T., J. L. Hutchison, and H. D. Norman. 2008. Modeling nuisance variables for prediction of service sire fertility. J. Dairy Sci. 91:2823-2835.

Norman, H. D., J. L. Hutchison, and J. R. Wright. 2008a. Sire conception rate: New national AI bull fertility evaluation. AIPL Res. Rep. SCR1 (7-08). Accessed Sep. 17, 2012. http://aipl.arsusda. gov/reference/arr-scr1.htm.

Norman, H. D., J. L. Hutchison, J. R. Wright, and S. M. Hubbard 2008b. A national sire fertility index. Pages $45-52$ in Proc. Dairy Cattle Reproductive Council Conf., Omaha, NE. Dairy Cattle Reproductive Council, Hartland, WI.

Oseni, S., S. Tsuruta, I. Misztal, and R. Rekaya. 2004. Genetic parameters for days open and pregnancy rates in US Holsteins using different editing criteria. J. Dairy Sci. 87:4327-4333.

SAS Institute. 2011. SAS 9.3 product documentation. Accessed Mar. 29, 2012. http://support.sas.com/documentation/93/index.html.

Weigel, K. A. 2004. Improving the reproductive efficiency of dairy cattle through genetic selection. J. Dairy Sci. 87(E. Suppl.):E86E92. 